\title{
Atorvastatin improves left ventricular remodeling and cardiac function in rats with congestive heart failure by inhibiting RhoA/Rho kinase-mediated endothelial nitric oxide synthase
}

\author{
LIPING AN ${ }^{1}$, SHOUKUAN AN ${ }^{2}$, ZHUOWEN JIA ${ }^{1}$, HUAN WANG $^{1}$, ZHAOYING YANG $^{1}$, CHAOXIN XU $^{1}$, \\ XIANE TENG $^{1}$, JIPENG WANG ${ }^{1}$, XIAODONG LIU $^{1}$, QIDONG CAO $^{1}$ and SHA WANG ${ }^{1}$ \\ ${ }^{1}$ Department of Geriatric Cardiology, Heilongjiang Provincial Hospital, Harbin, Heilongjiang 150036; \\ ${ }^{2}$ Department of Cardiac Surgery, The Second Affiliated Hospital of Harbin Medical University, \\ Harbin, Heilongjiang 150086, P.R. China
}

Received January 12, 2017; Accepted November 3, 2017

DOI: $10.3892 /$ etm.2018.6976

\begin{abstract}
The aim of the present study was to investigate the effects and possible mechanisms of atorvastatin (Ato) against chronic heart failure (CHF). A rat model of CHF was established and cardiac functions were assessed using Echocardiography. The expression of RhoA/Rho kinase and endothelial nitric oxide synthase (eNOS) was assessed using western blotting and reverse transcription polymerase chain reaction following 4 weeks of treatment. The three groups assessed in the present study were as follows: The control group (no treatment), the Ato + isopropylnoradrenaline (ISO) group (subcutaneous injections of $340 \mathrm{mg} / \mathrm{kg}$ ISO + orally administered $50 \mathrm{mg} / \mathrm{kg}$ Ato dissolved in saline; administered once daily) and the ISO group (subcutaneous injections of $340 \mathrm{mg} / \mathrm{kg}$ ISO + orally administered with an equal volume of saline; administered once daily). Heart volume and weight in the ISO group were significantly increased compared with the control (C) group $(\mathrm{P}<0.01)$, whereas contractility was decreased. The results were reverse for the Ato group when compared with the ISO group $(\mathrm{P}<0.05)$. Levels of RhoA/Rho kinase protein and mRNA were significantly increased in the ISO group $(\mathrm{P}<0.01)$; however. The mRNA and protein expression of eNOS was significantly decreased $(\mathrm{P}<0.05)$ when compared with the $\mathrm{C}$ group. The mRNA and protein expression of RhoA/Rho kinase was significantly reduced in the Ato+ISO group compared with the ISO group $(\mathrm{P}<0.01)$, whereas the mRNA and protein expression of eNOS was significantly increased $(\mathrm{P}<0.05)$. RhoA protein
\end{abstract}

Correspondence to: Professor Shoukuan An, Department of Cardiac Surgery, The Second Affiliated Hospital of Harbin Medical University, 246 Xuefu Road, Nangang, Harbin, Heilongjiang 150086, P.R. China

E-mail: shoukuanan@126.com

Key words: left ventricular remodeling, atorvastatin, small GTP-binding protein RhoA, Rho kinase, endothelial nitric oxide synthase expression was increased in the cytoplasm of the $\mathrm{C}$ group and on the cell membrane of the ISO group; however, in the Ato+ISO group, RhoA protein expression on the cell membrane was significantly downregulated when compared with the ISO group $(\mathrm{P}<0.05)$. The results of the present study suggest that Ato upregulates eNOS by inhibiting RhoA/Rho kinase overexpression in the myocardial tissue of rats with CHF, thus improving left ventricular remodeling and cardiac function.

\section{Introduction}

Heart failure (HF) is characterized by functional and structural cardiac abnormalities, progressively leading to clinical symptoms and signs (1). The sympathetic nervous system, the rennin-angiotensin-aldosterone system, the natiuretic peptide system and interactions between endothelial, monocytes/macrophages and myocardial cells serve primary roles in HF pathophysiology (2-6). These can cause endothelial dysfunction, oxidative stress, inflammation, thrombosis, adverse cardiac remodeling and haemodynamic disorders (2-6). At present, treatment of HF includes drug therapy, cardiac resynchronization therapy, left ventricular assist devices and revascularization, lifestyle interventions (7). Drug therapy that aims to adequately decongest the volume overload state consists of angiotensin converting enzyme inhibitors/angiotensin-II receptor blockers, mineralocorticoid receptor antagonists, beta-blockers, vasopressin antagonists, angiotensin receptor-neprilysin inhibitors and diuretics $(8,9)$. Common adverse effects of pharmacotherapy include abnormal water homeostasis, worsening kidney function, electrolyte disturbances and drug-drug interactions $(8,9)$. Resistance to diuretics and the associated morbidities have led to the development of effective and safe treatment strategies that maximize decongestion but minimize the adverse impact on kidney function $(8,9)$.

Statins are types of lipid regulating medicines. They lower cholesterol by inhibiting HMG-CoA reductase (10). In addition, statins exhibit various pleiotropic effects, including improvement in endothelial dysfunction, increased nitricoxide bioavailability, antioxidant properties, reduction of blood thrombogenicity, and inhibition of proinflammatory responses (10-12). 
Previous studies have reported that statins are able to induce left ventricular remodeling and improve cardiac function in rats with experimental myocardial infarction $(13,14)$. A number of clinical trials have demonstrated that treatment with statins improves the prognosis of patients with heart failure (HF) (15-17). Patients with HF have been reported to benefit from statin treatment irrespective of cholesterol levels, atherosclerosis or the root cause of HF (18). However, the exact mechanism for this is yet to be elucidated. Small GTP-binding protein RhoA and its downstream signal transduction protein, Rho kinase, participate in several cell signaling functions, including cell proliferation, smooth muscle and myocardial contraction, cytoskeleton re-arrangement, cell migration and proliferation (19). Previous animal studies have indicated that the RhoA/Rho kinase signaling pathway serves an important role in left ventricular remodeling of HF (19-21). The RhoA/Rho-kinase pathway is known to serve a number of important roles in cellular functions, including contraction, motility (22), proliferation and apoptosis; excessive activation of this pathway induces oxidative stress and increases the risk of cardiovascular diseases (23). In the present study, an isopropylnoradrenaline (ISO)-induced chronic HF (CHF) rat model was established to investigate the roles of the RhoA/Rho kinase signaling pathway in left ventricular remodeling, as well as the treatment effect of atorvastatin (Ato). The aim of the present study was to explore the effects and possible mechanisms of Ato as a preventative measure and treatment for $\mathrm{HF}$ to provide a theoretical basis for its clinical use.

\section{Materials and methods}

Animals, grouping and treatment. A total of 95 6-8 week old male Wistar rats (220-250 g) were provided by the Experimental Animal Center of Harbin Medical University (Harbin, China). Rats were housed at a temperature of $23 \pm 2^{\circ} \mathrm{C}$ and a humidity of $50 \%$. Animals were subjected to a $12 \mathrm{~h}$ light/dark cycle and standard rat chow and tap water were available ad libitum. Rats were randomly divided into 2 groups: The control group $(C ; n=15)$ and the HF group $(n=80)$. The HF group was administered with subcutaneous injections of $340 \mathrm{mg} / \mathrm{kg}$ ISO (Sigma-Aldrich; Merck KGaA, Darmstadt, Germany) twice with an interval of $24 \mathrm{~h}$. At 2 months post-injection, a total of 34 rats in the HF group had survived. HF rats were subsequently randomly divided into two groups: The ISO + Ato group $(n=17$; orally administered with $50 \mathrm{mg} / \mathrm{kg}$ Ato dissolved in saline once daily) and the ISO group ( $n=17$; orally administered with an equal volume of saline once daily). Ato was supplied by Pfizer, Inc. (New York, NY, USA). No additional treatments were administered to the $\mathrm{C}$ group. A total of 14 rats in the ISO+Ato group, 11 rats in the ISO group and 15 rats in the C group survived following 4 weeks of continuous treatment. The animal use protocol has been reviewed and approved by the Institutional Animal Care and Use Committee of Heilongjiang Provincial Hospital (Harbin, China).

Echocardiography. A Philips SONOS 7500 ultrasound scanner (Philips Medical Systems, Inc., Bothell, WA, USA) was used for ECG. Each rat was anesthetized by an intraperitoneal injection of $30 \mathrm{mg} / \mathrm{kg}$ sodium pentobarbital (Shanghai Yiji Industrial Co., Ltd., Shanghai, China) and the left ventricular
Table I. Comparison of ultrasound results among different groups.

\begin{tabular}{lcccc}
\hline Group & $\mathrm{n}$ & LVEDD $(\mathrm{mm})$ & $\operatorname{LVESD}(\mathrm{mm})$ & FS \\
\hline C & 15 & $4.2 \pm 0.5$ & $2.3 \pm 0.4$ & $0.46 \pm 0.03$ \\
ISO & 11 & $6.3 \pm 0.5^{\mathrm{a}}$ & $4.8 \pm 0.3^{\mathrm{a}}$ & $0.23 \pm 0.04^{\mathrm{a}}$ \\
ISO+Ato & 14 & $5.8 \pm 0.3^{\mathrm{a}, \mathrm{b}}$ & $3.8 \pm 0.2^{\mathrm{a}, \mathrm{b}}$ & $0.34 \pm 0.02^{\mathrm{a}, \mathrm{b}}$ \\
\hline
\end{tabular}

${ }^{\mathrm{a}} \mathrm{P}<0.01$ vs. group $\mathrm{C}$ and ${ }^{\mathrm{b}} \mathrm{P}<0.01$ vs. ISO group. LVEDD, left ventricular end-diastolic diameter; LVESD, left ventricular end-systolic diameter; FS, left ventricular fractional shortening; C, control; ISO, isopropylnoradrenaline; Ato, atorvastatin.

end-diastolic diameter (LVEDD), left ventricular end-systolic diameter (LVESD) and left ventricular fractional shortening (FS) were measured. Results were calculated automatically by the ultrasound system.

Determination of hemodynamics. Hemodynamic detection was performed immediately following. Following anesthesia of the rats with an intraperitoneal injection of $30 \mathrm{mg} / \mathrm{kg}$ sodium pentobarbital, the neck skin was cut open and the right common carotid artery was fully exposed approximately $1-1.5 \mathrm{~cm}$ long. Rats did not exhibit symptoms of peritonitis following the administration of anesthesia. The distal artery was ligated using a small arterial clip and then the proximal artery was ligated. The outside of the two arteries were tied using clips with surgical lines. The ligated arterial segment was then punctured and fixed with one heparin saline-rinsed micropressure sensing catheter. The artery clamp was opened and a catheter was inserted into the left ventricle. A micropressure sensor (YH type 4B physiological pressure sensor; Beijing Aerospace Medical Engineering Research Institute, Beijing, China) was used to determine left ventricular pressure changes at $400 \mathrm{~Hz}$. Spectrum software was used to analyze the left ventricular end diastolic pressure (LVEDP), the left ventricular end systolic pressure (LVESP), the maximal left ventricular pressure increase rate (dp/dtmax) and the maximal left ventricular pressure decrease rate (dp/dtmin).

Preservation of specimens. Following Echocardiography, $2 \mathrm{ml}$ of blood was extracted from the right ventricle, centrifuged at $559 \times \mathrm{g}$ for $15 \mathrm{~min}$ at $4^{\circ} \mathrm{C}$ and stored at $-70^{\circ} \mathrm{C}$. After extracting blood, rats were placed under general anesthesia as aforementioned. Each rat was euthanized $(75-150 \mathrm{mg} / \mathrm{kg}$ $\mathrm{KCl}$ intravenously into the femoral vein), Then, the heart was taken out and washed with ice-cold saline. The left and right atria, large blood vessels and attached connective tissue were removed, following which the left ventricle was dried using filter paper and weighed to calculate the left ventricular mass index (left ventricular weight/body weight). The free wall myocardial tissue was separated from the left ventricle. One partial left ventricular tissue was used for morphological detection. The remainder of the sample was used for molecular biological tests.

Measurement of total blood cholesterol. Plasma total cholesterol was determined enzymatically using commercially available reagent kit according to the manufacturer's protocol 
$A$ B C

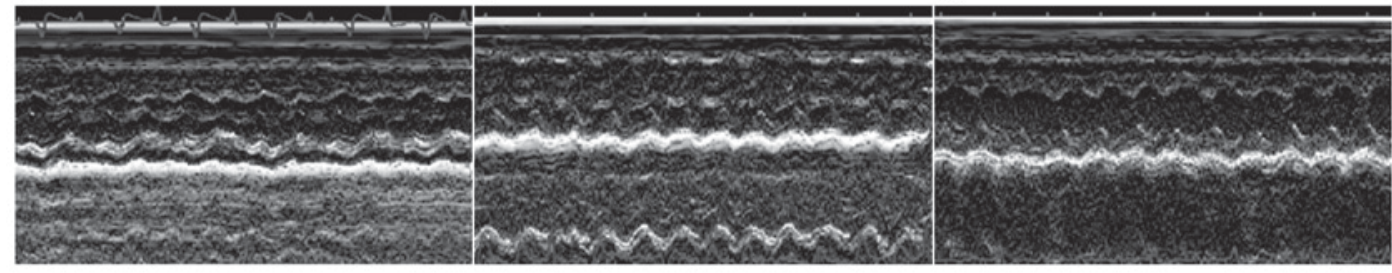

Figure 1. Left ventricular ultrasound of rats in the (A) control, (B) ISO and (C) ISO + Atorvastatin groups. ISO, isopropylnoradrenaline.

(Siemens Healthineers, Erlangen, Germany; ADVIA Chemistry CHOL_2; cat. no. 10376501) (24).

Cardiac morphological examination. Left ventricular tissue sections were fixed in $4 \%$ Bouins fluid at room temperature for $24 \mathrm{~h}$, dehydrated, chloroform transparentized and then immersed in paraffin. The paraffin-embedded ventricular samples were cut to $5 \mu \mathrm{m}$ sections for Masson staining at room temperature for 17-22 min, followed by the semi-quantitative analysis of collagens using a computer image analysis system (Three high CMIAS99C multifunctional real color pathological analysis system; Beijing University of Aeronautics and Astronautics, Beijing, China). Collagen volume fraction $=[$ area of collagen under the visual field/(area of collagen + area of myocardial tissue)].

Reverse transcription polymerase chain reaction ( $R T-P C R)$. Total RNA was extracted from the myocardial tissue by the two-step guanidinium isothiocyanate-phenol-chloroform method (25) and RT-PCR was performed according to the kit instructions (A3500 reverse transcription kit; Promega Corporation, Madison, WI, USA). The reaction mixture comprised primers, mRNA samples, Taq enzyme (Takara Bio, Inc., Otsu, Japan) and deionized water to give a final volume of $20 \mu \mathrm{l}$. RT was performed for $40 \mathrm{~min}$ at $42^{\circ} \mathrm{C}$. The PCR conditions were as follows: Pre-denaturation at $94^{\circ} \mathrm{C}$ for $5 \mathrm{~min}$, denaturation at $94^{\circ} \mathrm{C}$ for $30 \mathrm{sec}$, annealing at $60^{\circ} \mathrm{C}$ for $45 \mathrm{sec}$ and extension at $72^{\circ} \mathrm{C}$ for $10 \mathrm{~min}$ for 35 cycles, followed by an extension step at $72^{\circ} \mathrm{C}$ for $5 \mathrm{~min}$. Each PCR reaction was repeated at least 3 times. The primers were synthetized by Shanghai Bioasia Co., Ltd. (Shanghai, China) as follows: RhoA kinase (244 bp) forward, 5'-ACCAGTTCCCAGAGGTGTATG T-3' and reverse, 5'-TTGGGACAGAAGTGCTTGACTTC-3'; Rho kinase (512 bp) forward, 5'-GAGCAACTATGATGTGCC TGAAAAAT-3' and reverse, 5'-GATGTCGTTTGATTTCT TCTAC-3'; endothelial nitric oxide synthase (eNOS; 340 bp) forward, 5'-TACCGGCTGCCACCTGATCCTTAA-3' and reverse, 5'-AACATGTGTCCTTGCTCGAGGCA-3'; $\beta$-actin (276 bp) forward, 5'-TCATGCCATCCTGCGTCTG-3' and reverse, 5'-GCATCGGAACCGCTCATT-3'. A total of $5 \mu \mathrm{l}$ of the PCR products were then subjected to $1.5 \%$ agarose gel electrophoresis and analyzed by a gel imaging system (UV-visible light Gel detection and Imaging System; Kodak, Rochester, NY, USA) to calculate the ratios of the RhoA/Rho kinase and eNOS mRNA to $\beta$-actin.

Western blot analysis. RhoA and eNOS proteins were extracted from the cell membrane and cytoplasm as previously described $(20,21,26,27)$. A total of $100 \mathrm{mg}$ of left ventricular myocardial tissue was homogenized in $1 \mathrm{ml}$ of lysis buffer (Beyotime Institute of Biotechnology, Haimen, China) and centrifuged at $3,000 \mathrm{xg}$ at $4^{\circ} \mathrm{C}$ for $10 \mathrm{~min}$ to isolate the RhoA protein (in the supernatant) and the eNOS protein (in the precipitate; $3,000 \mathrm{xg}$ for $5 \mathrm{~min}$ at $4^{\circ} \mathrm{C}$ ), which were then centrifuged individually. The supernatant containing the RhoA protein was centrifuged at $3,000 \times \mathrm{g}$ for $30 \mathrm{~min}$ at $4^{\circ} \mathrm{C}$ to separate cell membrane and cytoplasmic proteins. Standard protein $(0.5 \mathrm{mg} / \mathrm{ml})$ with a volume of $0,1,2,4,8,12,16$ and $20 \mu \mathrm{l}$ was added to the standard pore of a 96-well plate. A total of $20,19,18,16,12,8,4$ and $0 \mu \mathrm{l}$ distilled $\mathrm{H}_{2} \mathrm{O}$ was then added to each pore with the standard protein. The sample preparation solution was then added to each well to make $1 \mu \mathrm{l}$. A total of $200 \mu \mathrm{l}$ BCA working fluid was added to each well and incubated at $56^{\circ} \mathrm{C}$ for $30 \mathrm{~min}$. Light density was measured at $562 \mathrm{~nm}$ using an enzyme scale ELIASA. Protein concentration was calculated based on the standard curve.

The protein solution was adjusted so as to achieve a consistent protein concentration. Proteins $(50 \mu \mathrm{g})$ were subsequently separated by SDS-PAGE using 15\% (RhoA) and 5\% (eNOS) isolation gel and 5\% spacer gel. Proteins were subsequently transferred onto a nitrocellulose membrane using the semi-dry electroblotting method (28), the membrane was washed with TBS three times for $5 \mathrm{~min}$, cultured in the blocking solution ( $98 \%$ bovine serum albumin; Sigma-Aldrich; Merck KGaA) for $30 \mathrm{~min}$ and incubated at $37^{\circ} \mathrm{C}$ for $1 \mathrm{~h}$ with the following primary multiclonal antibodies: Rabbit RhoA (1:500; cat. no. sant-sc-179; Santa Cruz Biotechnology, Inc., Dallas, TX, USA), eNOS (1:500; cat. no. FNABP0035; Wuhan Boster Biological Technology, Ltd., Wuhan, China) and $\beta$-actin (1:1,000; cat. no. TA-09; OriGene Technologies, Inc., Beijing, China) The membrane was subsequently washed with TBS four times for $5 \mathrm{~min}$ and incubated with horseradish peroxidase-labeled secondary rabbit anti-goat immunoglobulin $\mathrm{G}$ antibodies $(1: 5,000$; cat. no. HS-RG-HRP-100; Hebei Hanlin Biological Technology, Co., Ltd., China) for $30 \mathrm{~min}$ at $37^{\circ} \mathrm{C}$. The membrane was washed with TBST four times for $5 \mathrm{~min}$, TBS twice for $5 \mathrm{~min}$ and stained using a Beyo ECL kit (cat. no. P0018; Beyotime Institute of Biotechnology) for $3-5 \mathrm{~min}$ at $37^{\circ} \mathrm{C}$, following which the optical densities were analyzed using an optical density scanner (Universal Hood II 7218R02319; Bio-Rad Laboratories, Inc., Hercules, CA, USA).

Statistical analysis. All data were analyzed using SPSS version 12.0 (SPSS, Inc., Chicago, IL, USA) and expressed as the mean \pm standard deviation. One-way analysis of variance was used for multi-group comparisons, and a post-hoc q-test was used for further comparison. $\mathrm{P}<0.05$ was considered to indicate a statistically significant difference. 
Table II. Hemodynamic results.

\begin{tabular}{lccccc}
\hline Group & $\mathrm{n}$ & $\operatorname{LVESP}(\mathrm{mmHg})$ & $\operatorname{LVEDP}(\mathrm{mmHg})$ & $\mathrm{dp} / \mathrm{dt}_{\max }(\mathrm{mmHg} / \mathrm{sec})$ & $\mathrm{dp} / \mathrm{dt}_{\min }(\mathrm{mmHg} / \mathrm{sec})$ \\
\hline C & 15 & $112.6 \pm 3.4$ & $2.6 \pm 0.4$ & $11294 \pm 796$ & $-7351 \pm 684$ \\
ISO & 11 & $96.8 \pm 5.1^{\mathrm{a}}$ & $7.2 \pm 0.6^{\mathrm{a}}$ & $6879 \pm 512^{\mathrm{a}}$ & $-5426 \pm 526^{\mathrm{a}}$ \\
ISO+Ato & 14 & $106.3 \pm 4.3^{\mathrm{a}, \mathrm{b}}$ & $4.3 \pm 0.7^{\mathrm{a}, \mathrm{b}}$ & $8456 \pm 873^{\mathrm{a}, \mathrm{b}}$ & $-5986 \pm 398^{\mathrm{a}, \mathrm{b}}$
\end{tabular}

${ }^{\mathrm{a}} \mathrm{P}<0.01$ vs. group $\mathrm{C}$ and ${ }^{\mathrm{b}} \mathrm{P}<0.05$ vs. ISO group. LVESP, left ventricular end systolic pressure; LVEDP, left ventricular end diastolic pressure; $\mathrm{C}$, control; ISO, isopropylnoradrenaline; Ato, atorvastatin.

Table III. Left ventricular weight, body weight and left ventricular mass index.

\begin{tabular}{lcccc}
\hline Group & $\mathrm{n}$ & LVW $(\mathrm{mg})$ & BW $(\mathrm{g})$ & LVW/BW $(\mathrm{mg} / \mathrm{g})$ \\
\hline C & 15 & $767 \pm 13$ & $324 \pm 12$ & $2.37 \pm 0.38$ \\
ISO & 11 & $918 \pm 17^{\mathrm{a}}$ & $326 \pm 17$ & $2.80 \pm 0.43^{\mathrm{a}}$ \\
ISO+Ato & 14 & $871 \pm 20^{\mathrm{a}, \mathrm{b}}$ & $323 \pm 22$ & $2.68 \pm 0.48^{\mathrm{a}, \mathrm{b}}$ \\
\hline
\end{tabular}

${ }^{\mathrm{a}} \mathrm{P}<0.01$ vs. group $\mathrm{C}$ and ${ }^{\mathrm{b}} \mathrm{P}<0.05$ vs. ISO group. $\mathrm{LVW}$, left ventricular weight; BW, body weight; C, control; ISO, isopropylnoradrenaline; Ato, atorvastatin.

\section{Results}

Echocardiography. Compared with C group, the LVESD and LVEDD in the ISO group were significantly increased, whereas the FS was significantly deceased $(\mathrm{P}<0.01)$ (Fig. 1; Table I). The LVESD and LVEDD were significantly decreased in the ISO+Ato group compared with the ISO group, while the FS was significantly increased (Fig. 1; Table I).

Hemodynamic indices. Compared with the C group, the LVESP and dp/dtmax in the ISO group were significantly decreased $(\mathrm{P}<0.01)$, whereas the LVEDP and dp/dtmin were significantly increased $(\mathrm{P}<0.01)$ (Table II). In the ISO+Ato group, the LVESP and $\mathrm{dp} / \mathrm{dtmax}$ were significantly increased $(\mathrm{P}<0.05)$, whereas the LVEDP and dp/dtmin was significantly decreased when compared with the ISO group $(\mathrm{P}<0.05$; Table II).

Left ventricular weight, body weight and left ventricular mass index. Compared with the $\mathrm{C}$ group, left ventricular weight and left ventricular mass indices in the ISO and ISO+Ato groups were significantly increased $(\mathrm{P}<0.01)$. Compared with the ISO group, left ventricular weight and left ventricular mass index was decreased in the ISO+Ato group $(\mathrm{P}<0.05)$, whereas there was no significant difference in the body weight among the three groups (Table III).

Serum lipid level. No significant difference in the total cholesterol was observed between the ISO and $\mathrm{C}$ groups $(\mathrm{P}>0.05$; $1.55 \pm 0.084$ and $1.54 \pm 0.068 \mathrm{mmol} / \mathrm{l})$. Following 4 weeks of Ato treatment, total cholesterol in the ISO+Ato group was no significantly decreased compared with the ISO group $(\mathrm{P}>0.05$; Table IV).
Table IV. Effects of atorvastatin on serum TC.

\begin{tabular}{lll}
\hline Group & $\mathrm{n}$ & $\mathrm{TC}(\mathrm{mmo} / \mathrm{l})$ \\
\hline $\mathrm{C}$ & 15 & $1.54 \pm 0.068$ \\
ISO & 11 & $1.55 \pm 0.084^{\mathrm{a}}$ \\
ISO+Ato & 14 & $1.52 \pm 0.066^{\mathrm{b}}$ \\
\hline
\end{tabular}

${ }^{\mathrm{a}} \mathrm{P}>0.05$ vs. group $\mathrm{C}$ and ${ }^{\mathrm{b}} \mathrm{P}>0.05$ vs. ISO group. $\mathrm{C}$, control; ISO, isopropylnoradrenaline; Ato, atorvastatin; TC, total cholesterol.

Collagen volume fraction. The collagen volume fraction in group ISO and ISO+Ato were significantly higher compared with the $C$ group $(6.48 \pm 0.61,4.07 \pm 0.17$ vs. $1.67 \pm 0.19 \%$; $P<0.01$; Figs. 2 and 3); however, the myocardial collagen volume fraction in the ISO+Ato group was significantly lower compared with the ISO group (4.07 \pm 0.17 vs. $6.48 \pm 0.61 \%$; $P<0.05$; Figs. 2 and 3 ).

mRNA expression of RhoA/Rho kinase and eNOS. The results are expressed as the grey value ratios of RhoA/Rho kinase and eNOS mRNA to $\beta$-actin mRNA. The levels of RhoA/Rho kinase and eNOS mRNA are presented in Fig. 4. Compared with the $\mathrm{C}$ group, the expression of RhoA/Rho kinase mRNA was significantly increased in the ISO group $(\mathrm{P}<0.01)$, whereas the expression of eNOS mRNA was significantly decreased $(\mathrm{P}<0.05)$. Ato is able to significantly decrease the expression of RhoA/Rho kinase mRNA $(\mathrm{P}<0.01)$ and increase the expression of eNOS mRNA $(\mathrm{P}<0.05)$.

Expressions of RhoA and eNOS protein. Under normal conditions, the RhoA protein is mainly expressed in the cytoplasm; however, in rats with $\mathrm{CHF}$, expression is significantly increased $(\mathrm{P}<0.01)$ on the myocardial cell membrane (group ISO). Ato markedly reduces the expression of RhoA protein on the myocardial cell membrane (Fig. 5A and B). Compared with the $\mathrm{C}$ group, eNOS expression was downregulated in the ISO group and this effect was markedly reversed by Ato (Fig. 5C).

\section{Discussion}

It has been reported that high doses of ISO result in time and dose-dependent cardiac dysfunction; furthermore, 2-week application induces an increase in left ventricular filling pressure, left ventricular hypertrophy and left ventricular dilatation, thus leading to the decrease of cardiac functions (29). The results of the present study indicate that the FS, LVESP and dp/dtmax 
A

B

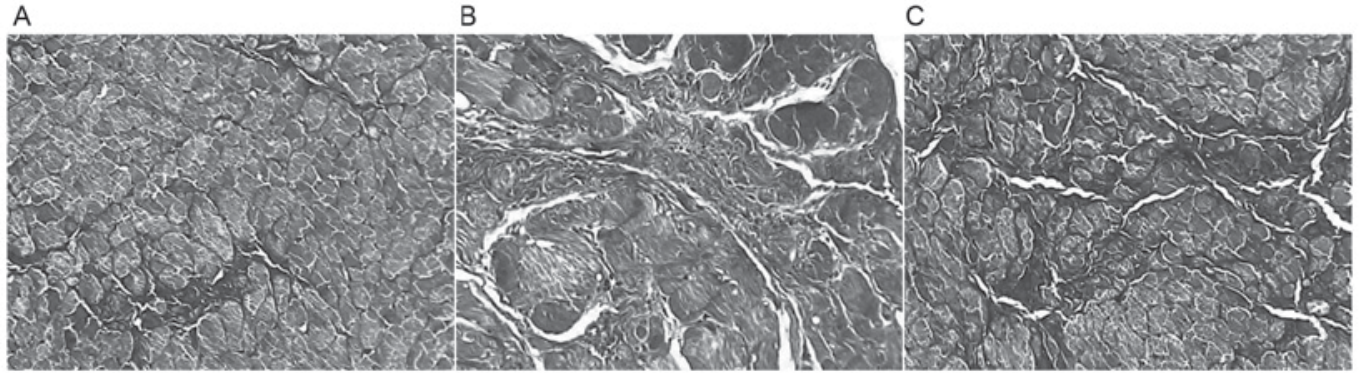

Figure 2. Masson staining of myocardial tissue in the (A) control, (B) ISO and (C) ISO + Atorvastatin groups. Magnification, x400. ISO, isopropylnoradrenaline.

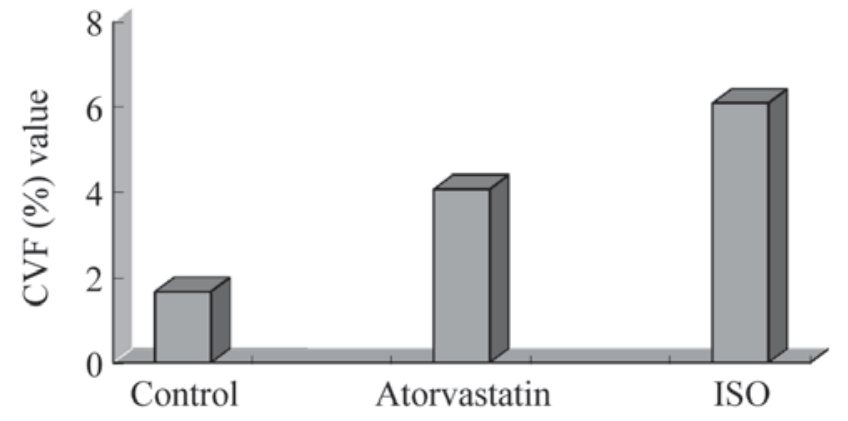

Figure 3. CVF value in the control, ISO and ISO + Atorvastatin groups.

in the ISO group were significantly decreased compared with the $\mathrm{C}$ group; however, the LVEDP and dp/dtmin were increased. This suggests that cardiac functions were decreased in the ISO group; however, the LVEDD, LVESD, left ventricular weight and left ventricular mass index were significantly increased, as well as the myocardial collagen volume fraction, which suggest that rats in the ISO group underwent cardiac remodeling.

Ato is a lipid-regulating statin that functions by inhibiting the synthesis of 3-hydroxy-3-methyl glutaryl coenzyme A reductase (30). However, its non-lipid-regulating roles have not yet been fully elucidated. The results of the present study demonstrated that FS, LVESP and dp/dtmax are significantly increased in rats with CHF following 4 weeks of Ato treatment, whereas the dp/dtmin, LVEDP, LVEDD, LVESD and left ventricular mass index are significantly decreased. The myocardial collagen volume fraction was also decreased; however, there was no significant reduction in blood cholesterol, indicating that Ato reduces left ventricular remodeling and improves cardiac function independently of cholesterol.

It was also observed that RhoA mRNA and protein in the ISO group were significantly upregulated compared with the $\mathrm{C}$ group and the expression of Rho kinase was significantly increased. This indicates that RhoA activation induces Rho kinase activation, thus leading to left ventricular remodeling and cardiac dysfunction. The mRNA and protein expression of RhoA in rats with CHF was decreased, whereas the mRNA expression of Rho kinase was downregulated, suggesting that Ato blocks the RhoA/Rho kinase pathway to improve ventricular remodeling and cardiac functions.

RhoA belongs to the small GTP-binding protein Rho family and is normally present in the cytoplasm in its inactive form, which undergoes isoprenylation due to the action of geranylgeranyl pyrophosphate (GGPP), is transferred onto the cell membrane and becomes the active form to serve its biological functions (19). It serves an important role in regulating the contraction of vascular smooth muscle cells and other cellular functions, including cell proliferation and migration (19). It has previously been reported that the RhoA/Rho kinase pathway is associated with hypertensive left ventricular hypertrophy and HF $(21,26,27,31)$. Hattori et al (32) demonstrated that the RhoA kinase pathway is associated with left ventricular remodeling in rats with experimental myocardial infarction. Dong et al (33) used a pressure overload-induced HF rat model to observe the roles of RhoA/Rho kinase; their results revealed that the RhoA/Rho kinase pathway participates in the occurrence and development of CHF. These findings indicate that RhoA and Rho kinases may be associated with the pathophysiology of cardiac dysfunction and cardiovascular remodeling, which is in agreement with the findings on the present study.

The mechanism of RhoA/Rho kinase-induced left ventricular remodeling in HF has not yet been determined. Kobayashi et al (21) applied RhoA-specific inhibitor Y-27632 to treat rats with CHF and salt-sensitive hypertension. The results indicated that Y-27632 inhibited RhoA, following which the expression of eNOS mRNA and protein increased, indicating that RhoA/Rho kinase induces left ventricular remodeling by inhibiting eNOS in the myocardium (34). Previous studies (35-37) have demonstrated that eNOS has beneficial effects on ventricular remodeling and improving cardiac functions. In the present study, the mRNA and protein expression of eNOS was significantly downregulated in the ISO group and upregulated following Ato treatment, indicating that Ato improves left ventricular remodeling and cardiac functions in rats with CHF by inhibiting the RhoA/Rho kinase pathway to upregulate eNOS expression.

Statins are able to block 3-hydroxy-3-methylglutaryl-coenzyme A (HMG-CoA) reductase, which reduces the cholesterol synthesis (30) and blocks the production of isoprenylated products in the mevalonate pathway (38). As RhoA protein can therefore not be prenylated, a large number of inactive RhoA protein accumulate in the cytoplasm, extending the half-life of eNOS mRNA (38).

In the present study, the roles of Ato in improving left ventricular remodeling and cardiac functions in rats with $\mathrm{CHF}$ were not associated with a reduction of blood cholesterol. A previous study also reported that competitive inhibitors of HMG-CoA reductase had no effect on blood cholesterol in rats, whereas they had been demonstrated to significantly reduce blood cholesterol in other species, including monkeys and 


\section{A (RhoA mRNA)}

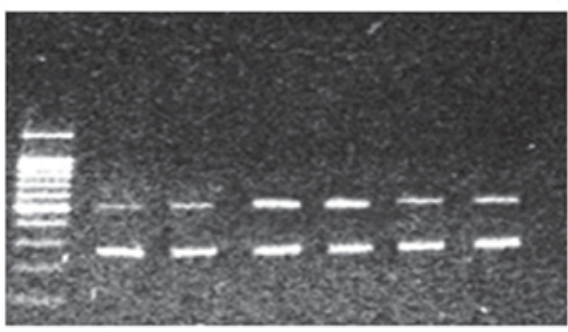

Control

ISO

Atorvastatin
B (Rho-kinase mRNA)

bp

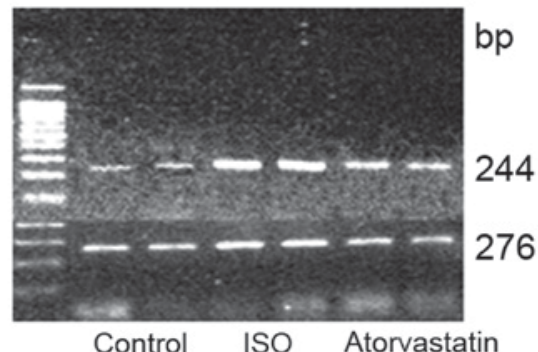

Control ISO Atorvastatin

\section{C (eNOS mRNA)}

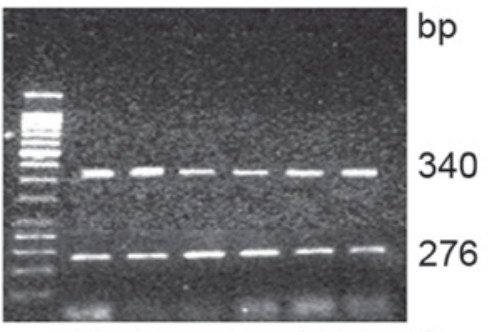

Control ISO Atorvastatin

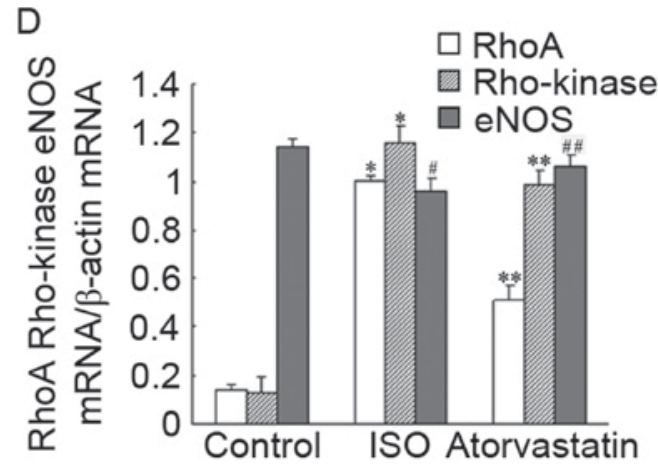

Figure 4. Detection of (A) RhoA, (B) Rho and (C) eNOS expression using reverse transcription polymerase chain analysis. (D) Quantified results. "P<0.01 and ${ }^{\#} \mathrm{P}<0.05$ vs. control; ${ }^{* *} \mathrm{P}<0.01$ and ${ }^{\# \#} \mathrm{P}<0.05$ vs. ISO. eNOS, endothelial nitric oxide synthase.

humans (39). The reason for this anomaly in rats has not been fully elucidated and may be associated with the activity increase of HMG-CoA reductase in rats' livers (35).

In conclusion, the findings of the present study indicate that Ato improves left ventricular remodeling and cardiac functions in rats with $\mathrm{CHF}$ by inhibiting RhoA/R ho kinase overexpression in the myocardial tissue, thereby further upregulating eNOS. Large-scale clinical trials are required to confirm these results and provide a clinical basis for the use of Ato as a treatment for CHF.

\section{Acknowledgements}

Not applicable.

\section{Funding}

No funding was received.

\section{Availability of data and materials}

The datasets used and/or analyzed during the current study are available from the corresponding author on reasonable request.

\section{Authors' contributions}

LA contributed to the conception of the study, and was a major contributor in writing the manuscript. SA wrote and revised the manuscript and gave final approval of the version to be published. ZJ performed the experiments and wrote the manuscript. HW contributed to the establishmen of animal models and specimen collection. ZY performed the experiments. CX performed the specimen collection. XT helped establish the

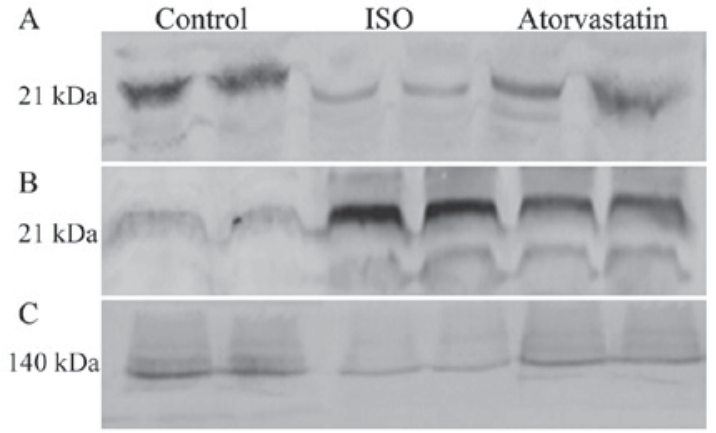

Figure 5. Impact of atorvastatin on (A) RhoA expression in the myocardial cytoplasm and (B) the cell membrane. (C) Impact of atorvastatin on eNOS protein in the myocardium.

animal models and performed the experiments. JW contributed to the determination of hemodynamics. XL performed the data analyses. QC analyzed and interpreted the data, and SW analyzed the data acquired.

\section{Ethics approval and consent to participate}

The animal use protocol has been reviewed and approved by the Institutional Animal Care and Use Committee of Heilongjiang Provincial Hospital.

\section{Patient consent for publication}

Not applicable.

\section{Competing interests}

The authors declare that they have no competing interests. 


\section{References}

1. Strandberg TE: Lipid-lowering drugs and heart failure: Where do we go after the statin trials? Curr Opin Cardiol 25: 385-393, 2010.

2. Volpe M, Carnovali $\mathbf{M}$ and Mastromarino V: The natriuretic peptides system in the pathophysiology of heart failure: From molecular basis to treatment. Clin Sci (Lond) 130: 57-77, 2016.

3. Glezeva N, Horgan S and Baugh JA: Monocyte and macrophage subsets along the continuum to heart failure: Misguided heroes or targetable villains? J Mol Cell Cardiol 89: 136-145, 2015.

4. Münzel T, Gori T, Keaney JF Jr, Maack C and Daiber A: Pathophysiological role of oxidative stress in systolic and diastolic heart failure and its therapeutic implications. Eur Heart J 36: 2555-2564, 2015

5. Shantsila E, Wrigley BJ, Blann AD, Gill PS and Lip GY: A contemporary view on endothelial function in heart failure. Eur J Heart Fail 14: 873-881, 2012.

6. Brower GL, Gardner JD, Forman MF, Murray DB, Voloshenyuk T, Levick SP and Janicki JS: The relationship between myocardial extracellular matrix remodeling and ventricular function. Eur J Cardiothorac Surg 30: 604-160, 2006.

7. Jin W: Heart failure, can be very special (N). Zhongguo yi xue lun tan bao Dec 16: 12-14, 2017 (In Chinese).

8. Freda BJ, Slawsky M, Mallidi J and Braden GL: Decongestive treatment of acute decompensated heart failure: Cardiorenal implications of ultrafiltration and diuretics. Am J Kidney Dis 58 1005-1017, 2011

9. Yancy CW, Jessup M, Bozkurt B, Butler J, Casey DE, Colvin MM, Drazner MH, Filippatos G, Fonarow GC, Givertz MM, et al: 2016 ACC/AHA/HFSA Focused update on new pharmacological therapy for heart failure: An update of the 2013 ACCF/AHA Guideline for the management of heart failure. A report of the American College of Cardiology/American Heart Association Task Force on Clinical Practice Guidelines and the Heart Failure Society of America. Circulation 134: e282-e293, 2016.

10. Babelova A, Sedding DG and Brandes RP: Anti-atherosclerotic mechanisms of statin therapy. Curr Opin Pharmacol 13: 260-264, 2013.

11. Birnbaum Y and Ye Y: Pleiotropic effect of statins: The role of eicosanoid production. Curr Atheroscler Aep 14: 135-139, 2012.

12. Wang CY, Liu PY and Liao JK: Pleiotropic effects of statin therapy: Molecular mechanisms and clinical results. Trends Mol Med 14: 37-44, 2008.

13. Bauersachs J, Galuppo P, Fraccarollo D, Christ M and Ertl G: Improvement of left ventricular remodeling and function by hydroxymethylglutaryl coenzyme a reductase inhibition with cerivastatin in rats with heart failure after myocardial infarction. Circulation 104: 982-985, 2001.

14. Hayashidani S, Tsutsui H, Shiomi T, Suematsu N, Kinugawa S, Ide T, Wen J and Takeshita A: Fluvastatin, a 3-hydroxy-3methylglutaryl coenzyme a reductase inhibitor, attenuates left ventricular remodeling and failure after experimental myocardial infarction. Circulation 105: 868-873, 2002.

15. Alehagen U, Benson L, Edner M, Dahlström U and Lund LH: Association between use of statins and mortality in patients with heart failure and ejection fraction of $\geq 50$. Circ Heart Fail 8 : $862-870,2015$

16. Wojnicz R, Wilczek K, Nowalany-Kozielska E, Szyguła-Jurkiewicz B, Nowak J, Poloński L, Dyrbuś K, Badziński A, Mercik G, Zembala M, et al: Usefulness of atorvastatin in patients with heart failure due to inflammatory dilated cardiomyopathy and elevated cholesterol levels. Am J Cardiol 97: 899-904, 2006

17. Sola S, Mir MQ, Lerakis S, Tandon N and Khan BV: Atorvastatin improves left ventricular systolic function and serum markers of inflammation in nonischemic heart failure. J Am Coll Cardiol 47: 332-337, 2006

18. Horwich TB, MacLllan R and Fonarow GC: Statin therapy is associated with improved survival in ischemic and non-ischemic heart failure. J Am Coll Cardiol 43: 642-648, 2004.

19. Ren J and Fang CX: Small guanine nucleotide-binding protein Rho and myocardial function. Acta Pharmacologica Sinica 26 279-285, 2005.

20. Kobayashi N, Horinaka S, Mita S, Nakano S, Honda T, Yoshida K, Kobayashi T and Matsuoka H: Critical role of Rho-kinase pathway for cardiac performance and remodeling in failing rat hearts Cardiovasc Res 55: 757-767, 2002.
21. Kobayashi N, Nakano S, Mita S, Kobayashi T, Honda T, Tsubokou $\mathrm{Y}$ and Matsuoka H: Involvement of Rho-kinase pathway for angiotensin II-induced plasminogen activator inhibitor-1 gene expression and cardiovascular remodeling in hypertensive rats. J Pharmacol Exp Ther 301: 459-466, 2002.

22. Serra N, Rosales R, Masana L and Vallvé JC: Simvastatin increases Fibulin-2 expression in human coronary artery smooth muscle cells via RhoA/Rho-Kinase signaling pathway inhibition. PLoS One 10: e0133875, 2015

23. Shimokawa H, Sunamura $S$ and Satoh K: RhoA/Rho-Kinase in the cardiovascular system. Circ Res 118: 352-366, 2016.

24. Li JZ: Method of determination of blood lipid recommended by Chinese Society of Laboratory Medicine: Serum total cholesterol determination by enzymatic method. Zhonghua jian yan yi xue za zhi 18: 185-187, 1995 (In Chinese).

25. Giovambattista A, Gaillard RC and Spinedi E: Ghrelin gene-related peptides modulate rat white adiposity. Vitam Horm 77: 171-205, 2008.

26. Landmesser U, Engberding N, Bahlmann FH, Schaefer A, Wiencke A, Heineke A, Spiekermann S, Hilfiker-Kleiner D, Templin C, Kotlarz D, et al: Statin-induced improvement of endothelial progenitor cell mobilization, myocardial neovascularization, left ventricular function, and survival after experimental myocardial infarction requires endothelial nitric oxide synthase. Circulation 110: 1933-1939, 2004.

27. Sauzeau V, Le Jeune H, Cario-Toumaniantz C, Smolenski A, Lohmann SM, Bertoglio J, Chardin P, Pacaud P and Loirand G: Cyclic GMP-dependent protein kinase signaling pathway inhibits RhoA-induced $\mathrm{Ca} 2+$ sensitization of contraction in vascular smooth muscle. J Biol Chem 275: 21722-21729, 2000.

28. Fleming JE and Paull TT: Semi-dry electroblotting of DNA. Biotechniques 6: 926, 928-929, 1988

29. Chappel GI, Rona G, Balazs T and Gaudry R: Comparison of cardiotoxic actions of certain sympathomimetic amines. Can J Biochem Physiol 37: 35-42, 1959.

30. Ray S, Jindal AK, Sengupta S and Sinha S: Statins: Can we advocate them for primary prevention of heart disease? Med J Armed Forces India 70: 270-273, 2014.

31. Satoh S, Ueda Y, Koyanagi M, Kadokami T, Sugano M, Yoshikawa Y and Makino N: Chronic inhibition of Rho kinase blunts the process of left ventricular hypertrophy leading to cardiac contractile dysfunction in hypertension-induced heart failure. J Mol Cell Cardiol 35: 59-70, 2003

32. Hattori T, Shimokawa H, Higashi M, Hiroki J, Mukai Y, Tsutsui H, Kaibuchi K and Takeshita A: Long-term inhibition of Rho-kinase suppresses left ventricular remodeling after myocardial infarction in mice. Circulation 109: 2234-2239, 2004

33. Dong M, Liao JK, Yan B, Li R, Zhang M and Yu CM: A combination of increased Rho kinase activity and N-terminal pro-B-type natriuretic peptide predicts worse cardiovascular outcome in patients with acute coronary syndrome. Int J Cardiol 167: 2813-2819, 2013.

34. Mutlu E, İlhan S, Onat E, Kara M and Sahna E: The effects of novokinin, an AT2 agonist, on blood pressure, vascular responses, and levels of ADMA, NADPH oxidase, and Rho kinase in hypertension induced by NOS inhibition and salt. Turk J Med Sci 46: 1249-1257, 2016

35. Mossion PB and Balligand JL: Modulation of cardiac contraction, relaxation and rate by the endothelial nitricoxide synthase (eNOS): Lessons from genetically modified mice. J Physiol 546: 63-75, 2003.

36. Koyanagi M, Egashira K, Kitamoto S, Ni W, Shimokawa H, Takeya M, Yoshimura T and Takeshita A: Role of monocyte chemoattractant protein-1 in cardiovascular remodeling induced by chronic blockade of nitric oxide synthesis. Circulation 102: 2243-2248, 2000

37. Talukder MA, Fujiki T, Morikawa K, Motoishi M, Matsuo Y, Hatanaka M, Tsutsui M, Takeshita A and Shimokawa $\mathrm{H}$ : Endothelial nitric oxide synthase-independent effects of an ACE inhibition on coronary flow response to bradykinin in aged mice. J Cardiovasc Pharmacol 44: 557-563, 2004.

38. Laufs U, Endres M, Stagliano N, Amin-Hanjani S, Chui DS, Yang SX, Simoncini T, Yamada M, Rabkin E, Allen PG, et al: Neuroprotection mediated by changes in the endothelial actin cytoskeleton. J Clin Invest 106: 15-24, 2000.

39. Endo A, Tsujita Y, Kuroda M and Tanzawa K: Effects of ML-236B on cholesterol metabolism in mice and rats: Lack of hypocholesterolemic activity in normal animals. Biochim Biophys Acta 575: 266-276, 1979. 